\title{
Design High Efficiency Intelligent Robust Back stepping Controller
}

\author{
Kamran Heidari, Farzin Piltan, Samaneh Zahmatkesh, Sara Heidari, Mahdi Jafari \\ Institute of Advance Science and Technology, Intelligent control and Robotics Lab. IRAN SSP, Shiraz/Iran, \\ http://WWW.IRANSSP.COM \\ Email: Piltan_f@iranssp.com
}

\begin{abstract}
The increasing demand for multi-degree-offreedom (DOF) continuum robot in presence of highly nonlinear dynamic parameters in a number of industries has motivated a flurry of research in the development of soft computing nonlinear methodology. This research contributes to the on-going research effort by exploring alternate methods for controlling the continuum robot manipulator. This research addresses two basic issues related to the control of a continuum robots; (1) a more accurate representation of the dynamic model of an existing prototype, and (2) the design of a robust feedback controller. The robust back stepping controller proposed in this research is used to further demonstrate the appealing features exhibited by the continuum robot. Robust feedback controller is used to position control of continuum robot in presence of uncertainties. Using Lyapunov type stability arguments, a robust back stepping controller is designed to achieve this objective. The controller developed in this research is designed into two steps. Firstly, a robust stabilizing torque is designed for the nominal continuum robot dynamics derived using the constrained Lagrangian formulation. Next, the fuzzy logic methodology applied to it to solution uncertainty problem. The fuzzy model free problem is formulated to minimize the nonlinear formulation of continuum robot. The eventual stability of the controller depends on the torque generating capabilities of the continuum robots.
\end{abstract}

Index Term - Back stepping control methodology, fuzzy inference system, continuum robot manipulator, robust control.

\section{Introduction}

The designed controller not only demonstrates the appealing features exhibited by the spherical motor, but also demonstrates some of the nice features of Back stepping-type controllers as well. The work done in this research contributes to bringing the continuum robot a step closer to practical industrial application. Controller is a device which can sense information from linear or nonlinear system (e.g., continuum robot) to improve the systems performance [1-5]. The main targets in designing control systems are stability, good disturbance rejection, and small tracking error[6-12]. Several continuum robot are controlled by linear methodologies (e.g., Proportional-Derivative (PD) controller, Proportional-
Integral (PI) controller or Proportional- IntegralDerivative (PID) controller), but when robot works with various payloads and have uncertainty in dynamic models this technique has limitations. In some applications continuum robot are used in an unknown and unstructured environment, therefore strong mathematical tools used in new control methodologies to design nonlinear robust controller with an acceptable performance (e.g., minimum error, good trajectory, disturbance rejection) [12-15].

Advanced control techniques such as integrator Back stepping, feedback linearization, adaptive and robust have been applied to the control of numerous single- axis machines and robotic manipulators. Since available control techniques for continuum robot and robotic manipulators are so broad, the review in this research is restricted to some of the nonlinear control techniques for continuum robot. Most of the authors referenced on the nonlinear control techniques for continuum robot also do a significant amount of work on the control of robotic manipulators. Kokotovic [14-16] published one of the pioneering works on the back stepping control technique and $\mathrm{Qu}$ et al. [14] extended this technique and developed a robust back stepping-type controller for a one-link robot with the motor dynamics taken into consideration. Carroll et al. [15] also extended the work of Kokotovic [16] to design an embedded computed torque and output feedback controller for penitent magnet brush de (BDC) motors. Hematite et al. [16] developed a robust feedback linear zing controller for a single-link robot actuated by a brushless de motor (BLOC). In [17], Carroll et al. also developed a robust tracking controller for a BLOC, which achieved globally bounded results for rotor position tracking error despite parametric uncertainties and additive bounded disturbances. In addition to DC machines, SR and PM stepper motors are also candidates for advanced nonlinear controllers. In [18], Die'-Spong et al. introduced a detailed nonlinear model and an electronic commutation strategy for the SR motor and applied a state feedback control algorithm which compensated for all the nonlinearities of the system. The work in [18] was then generalized to a direct-drive manipulator with SR actuation by Taylor et al. [19]. Carroll et al. [20] also used a back stepping technique to develop an adaptive tracking controller for the SR motor. Bodson [21] developed a model-based control law for the PM stepper motor using an exact linearization methodology while considering practical issues such as 
voltage saturation. Even though some of the above control techniques are not of the back stepping type controller, the back stepping-type controller developed in this thesis was somewhat inspired by them.

In recent years, artificial intelligence theory has been used in nonlinear control systems. Neural network, fuzzy logic, and neuro-fuzzy are synergically combined with nonlinear classical controller and used in nonlinear, time variant, and uncertainty plant (e.g., robot manipulator). Fuzzy logic controller (FLC) is one of the most important applications of fuzzy logic theory. This controller can be used to control nonlinear, uncertain, and noisy systems. This method is free of some model-based techniques as in classical controllers. As mentioned that fuzzy logic application is not only limited to the modeling of nonlinear systems [22-37]but also this method can help engineers to design easier controller. Control robot arm manipulators using classical controllers are based on manipulator dynamic model. These controllers often have many problems for modelling. Conventional controllers require accurate information of dynamic model of robot manipulator, but these models are multi-input, multioutput and non-linear and calculate accurate model can be very difficult. When the system model is unknown or when it is known but complicated, it is difficult or impossible to use classical mathematics to process this model[32]. The main reasons to use fuzzy logic technology are able to give approximate recommended solution for unclear and complicated systems to easy understanding and flexible. Fuzzy logic provides a method which is able to model a controller for nonlinear plant with a set of IF-THEN rules, or it can identify the control actions and describe them by using fuzzy rules. It should be mentioned that application of fuzzy logic is not limited to a system that's difficult for modeling, but it can be used in clear systems that have complicated mathematics models because most of the time it can be shortened in design but there is no high quality design just sometimes we can find design with high quality. Besides using fuzzy logic in the main controller of a control loop, it can be used to design adaptive control, tuning parameters, working in a parallel with the classical and non classical control method [32-39]. The applications of artificial intelligence such as neural networks and fuzzy logic in modelling and control are significantly growing especially in recent years. For instance, the applications of artificial intelligence, neural networks and fuzzy logic, on robot arm control have reported in [40-57].

A serial link continuum robot is a sequence of joints and links which begins with a base frame and ends with an end-effector. This type of robot manipulators, comparing with the load capacitance is more weightily because each link must be supported the weights of all next links and actuators between the present link and endeffector[12-18]. Serial continuum robot manipulators have been used in medical application, and also in research laboratories. One of the most important classifications in controlling the robot manipulator is how the links have connected to the actuators. This classification divides into two main groups: highly geared (e.g., 200 to 1) and direct drive (e.g., 1 to 1). High gear ratios reduce the nonlinear coupling dynamic parameters in robot manipulator. In this case, each joint is modeled the same as SISO systems. In high gear robot manipulators which generally are used in industry, the couplings are modeled as a disturbance for SISO systems. Direct drive increases the coupling of nonlinear dynamic parameters of robot manipulators. This effect should be considered in the design of control systems. As a result some control and robotic researchers' works on nonlinear robust controller design[19-24]. Most of continuum robot manipulator is high gear, so this research focuses on design SISO controller.

This paper is organized as follows; section 2, is served as an introduction to the feedback back stepping controller formulation algorithm and its application to control of continuum robot and dynamic of continuum robot. Part 3, introduces and describes the methodology. Section 4 presents the simulation results and discussion of this algorithm applied to a continuum robot and the final section is describing the conclusion.

\section{Theory}

Dynamic Formulation of Continuum Robot: The Continuum section analytical model developed here consists of three modules stacked together in series. In general, the model will be a more precise replication of the behavior of a continuum arm with a greater of modules included in series. However, we will show that three modules effectively represent the dynamic behavior of the hardware, so more complex models are not motivated. Thus, the constant curvature bend exhibited by the section is incorporated inherently within the model. The model resulting from the application of Lagrange's equations of motion obtained for this system can be represented in the form

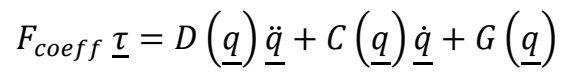

where $\tau$ is a vector of input forces and $\mathrm{q}$ is a vector of generalized co-ordinates. The force coefficient matrix $\mathrm{F}_{\text {coeff }}$ transforms the input forces to the generalized forces and torques in the system. The inertia matrix, D is composed of four block matrices. The block matrices that correspond to pure linear accelerations and pure angular accelerations in the system (on the top left and on the bottom right) are symmetric. The matrix $\mathrm{C}$ contains coefficients of the first order derivatives of the generalized co-ordinates. Since the system is nonlinear, many elements of $\mathrm{C}$ contain first order derivatives of the generalized co-ordinates. The remaining terms in the dynamic equations resulting from gravitational potential energies and spring energies are collected in the matrix $G$. The coefficient matrices of the dynamic equations are given below, 


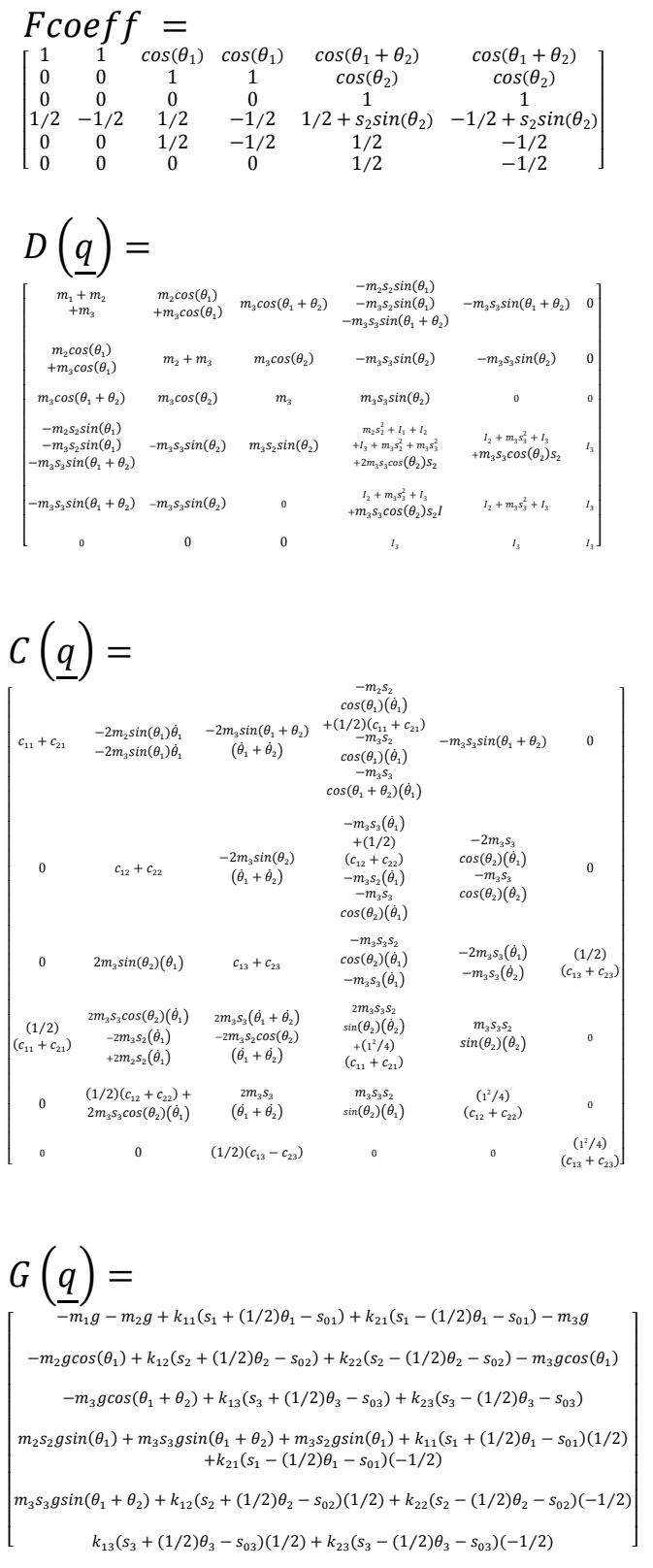

Backstepping Controller: The continuum robot dynamics in Equation (1) have the appropriate structure for the so-called back stepping controller design method. The steps in the back stepping controller design method are outlined in Figure 2. With the position error defined as $Z_{1}=X_{d}-X_{a}$, all joints will track the desired specified state $X_{d}$ if the error dynamics are given as follows:

$$
\left(\dot{\mathrm{Z}}_{1}+\left[\mathrm{K}_{\mathrm{p}}\right] \mathrm{Z}_{1}\right)=0
$$

where $\left[K_{p}\right]$ is a positive definite gain matrix. The error dynamics in Equation (6) can be rewritten as:

$$
\mathrm{X}_{2}=\dot{\mathrm{X}_{\mathrm{d}}}+\left[\mathrm{K}_{\mathrm{p}}\right] \mathrm{Z}_{1}
$$

Substitution of Equation (7) into Equation (1) makes the position error dynamics go to zero. Since the state vector $x_{2}$ is not a control variable, Equation (7) cannot be directly substituted into Equation (1). The expression in Equation (7) is therefore defined as a fictitious control input and is labeled expressed below as $\mathrm{X}_{2 \mathrm{~d}}$.

$$
\mathrm{X}_{2_{\mathrm{d}}}=\dot{\mathrm{X}}_{1_{\mathrm{d}}}+\left[\mathrm{K}_{\mathrm{p}}\right]\left(X_{d}-X_{a}\right)
$$

The fictitious control input in Equation (8) is selected as the specified velocity trajectory and hence the velocity error can be defined as $Z_{2}=X_{2_{d}}-X_{2_{a}}$. With the following dynamics

$$
\left(\dot{\mathrm{Z}}_{2}+\left[\mathrm{K}_{\mathrm{p}}\right] \mathrm{Z}_{2}\right)=0
$$

the joint position error will approach zero asymptotically, which will lead to the eventual asymptotic convergence of the joint position error. The error dynamics in equation (9) can be rewritten as:

$$
\mathrm{X}_{2}=\dot{\mathrm{X}_{\mathrm{d}}}+\left[\mathrm{K}_{\mathrm{p}}\right] \mathrm{Z}_{2}
$$

Substitution of Equation (9) into Equation (1) leads to the following expression as the desired stabilizing torque:

$$
\tau=[\mathrm{H}]\left(\dot{\mathrm{X}}_{2 \mathrm{~d}}+\left[\mathrm{K}_{\mathrm{p}}\right] \mathrm{Z}_{2}\right)+\mathrm{C}\left(\mathrm{X}_{1}, \mathrm{X}_{2}\right)
$$

The desired torque control input is a nonlinear compensator since it depends on the dynamics of the spherical motor. The time derivative of desired velocity vector is calculated using Equation (9). In terms of the desired state trajectory, and its time derivatives and the position and velocity state variables, the desired torque can be rewritten in following form:

$$
\tau=[H] y+C\left(X_{1}, X_{2}\right)
$$

Where

$$
\begin{aligned}
& \mathrm{y}=\ddot{\mathrm{X}}_{1_{\mathrm{d}}}+\left(\left[\mathrm{K}_{\mathrm{p}}\right]+\left[\mathrm{K}_{\mathrm{d}}\right]\right)\left(\dot{\mathrm{X}}_{1_{\mathrm{d}}}-\dot{\mathrm{X}}_{1}\right)+ \\
& \left(\left[\mathrm{K}_{\mathrm{p}}\right]\left[\mathrm{K}_{\mathrm{d}}\right] X_{d}-X_{a}\right.
\end{aligned}
$$

The back stepping controller developed above is very similar to inverse dynamics control algorithm developed for robotic manipulators. The back stepping controller is ideal from a control point of view as the nonlinear dynamics of the continuum robot are cancelled and replaced by linear subsystems. The drawback of the back stepping controller is that it requires perfect cancellation of the nonlinear continuum robot dynamics. Accurate real time representations of the robot dynamics are difficulty due to uncertainties in the system dynamics resulting from imperfect knowledge of the robot mechanical parameters; existence of unmolded dynamics and dynamic uncertainties due to payloads. The requirement for perfect dynamic cancellation raises sensitivity and robustness issues that are addressed in the design of a robust back stepping controller. Another drawback of the back stepping controller is felt during real-time implementation of the control algorithm. Implementation of the back stepping controller requires 
the computation of the exact robot dynamics at each sampling time. This computational burden has an effect on the performance of the control algorithm and imposes constraints on the hardware/software architecture of the control system. By only computing the dominant parts of the robot dynamics, this computational burden can be reduced. These drawbacks of the back stepping controller makes it necessary to consider control algorithms that compensate for both model uncertainties and for approximations made during the on-line computation of robot dynamics. The next section provides robust modifications of the back stepping controller described in this section. Figure 1 shows the block diagram of back stepping controller

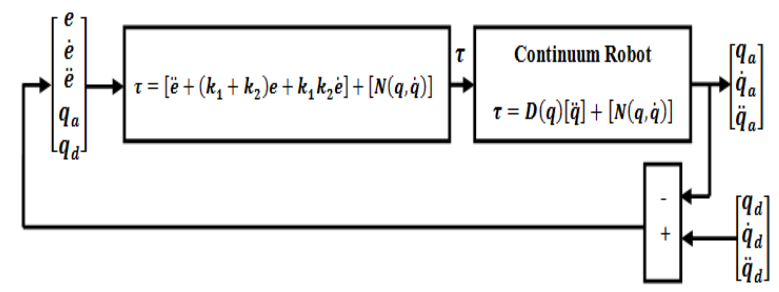

Figure 1. Block diagram of robust back stepping controller

Robust Back stepping Control: When there are uncertainties in the spherical motor dynamics due to modeling inaccuracy and computational relaxation, robust controllers are ideal for ensuring system stability. When the system dynamics are completely known, the required torque control vector for the control of the spherical motor is given by Equations (12) and (13). In the presence of modeling uncertainties, a reasonable approximation of the torque control input vector is given by

$$
T_{d}=[\widehat{H}] y+\hat{C}
$$

where $[\widehat{H}]$ and $\hat{C}$ are estimates of the inertia and coriolis terms in the spherical motor dynamics; and $y$ is given by Equation (13). The uncertainty on the estimates are expressed as

$$
\begin{aligned}
& {[\widetilde{H}]=[\widehat{H}]-[H]} \\
& {[\tilde{C}]=[\hat{C}]-[C]}
\end{aligned}
$$

These uncertainties account for both imperfect modeling and intentional computational simplification. Application of the approximate control vector given by Equations (14) leads to the following expression for the closed loop dynamics:

$$
[H] \dot{x}_{2}+C=[\widehat{H}] y+\hat{C}
$$

Since the inertia matrix $[\mathrm{H}]$ is symmetric and positive definite, the closed loop dynamics in Equation (17) can be rewritten as

$$
\ddot{x}_{1}=y-\eta
$$

where

$$
\eta=\left([I]-[H]^{-1}[\widehat{H}]\right) y-[H]^{-1} \tilde{C}
$$

Substitution of Equation (13) for $\boldsymbol{y}$ in Equation (18) results in the following expression for the closed loop error dynamics.

$$
\ddot{\tilde{x}}_{1}+\left(\left[K_{p}\right]+\left[K_{d}\right]\right) \dot{\tilde{x}}_{1}+\left[K_{p}\right]\left[K_{d}\right] \tilde{x}_{1}=\eta
$$

Defining a new error state vector,

$$
\xi=\left[\begin{array}{c}
\tilde{x}_{1} \\
\dot{\tilde{x}}_{1}
\end{array}\right]
$$

the error dynamics in Equation (20) can be expressed as

$$
\dot{\xi}=[F] \xi+[D]\left(\ddot{\mathrm{x}}_{1 \mathrm{~d}}-\mathrm{y}+\eta\right)
$$

Where $[F]=\left[\begin{array}{ll}{[0]} & {[1]} \\ {[0]} & {[0]}\end{array}\right]$ and $[D]=\left[\begin{array}{l}{[0]} \\ {[1]}\end{array}\right]$ are block matrices of dimensions $R^{6 \times 6}$ and $R^{6 \times 3}$ respectively. Since $\boldsymbol{\eta}$ is a nonlinear function of the position and velocity state vectors, the system error dynamics in the above equation are nonlinear and coupled. The back stepping controller developed in the previous section cannot guarantee system stability. The Lyapunov direct method is, however, used to design an outer feedback loop on the error dynamics that compensates for the system uncertainty contributed by $\boldsymbol{\eta}$.

Fuzzy Inference Engine: This section provides a review about foundation of fuzzy logic based on [15-20]. Supposed that $U$ is the universe of discourse and $x$ is the element of $U$, therefore, a crisp set can be defined as a set which consists of different elements $(x)$ will all or no membership in a set. A fuzzy set is a set that each element has a membership grade, therefore it can be written by the following definition;

$$
A=\left\{x, \mu_{A}(x) \mid x \in X\right\} ; A \in U
$$

Where an element of universe of discourse is $x, \mu_{A}$ is the membership function (MF) of fuzzy set. The membership function $\left(\mu_{A}(x)\right)$ of fuzzy set $A$ must have a value between zero and one. If the membership function $\mu_{A}(x)$ value equal to zero or one, this set change to a crisp set but if it has a value between zero and one, it is a fuzzy set. Defining membership function for fuzzy sets has divided into two main groups; namely; numerical and functional method, which in numerical method each number has different degrees of membership function and functional method used standard functions in fuzzy sets. The membership function which is often used in practical applications includes triangular form, trapezoidal form, bell-shaped form, and Gaussian form.

Linguistic variable can open a wide area to use of fuzzy logic theory in many applications (e.g., control and 
system identification). In a natural artificial language all numbers replaced by words or sentences.

If - then Rule statements are used to formulate the condition statements in fuzzy logic. A single fuzzy If - then rule can be written by

$$
\text { If } x \text { is } A \text { Then } y \text { is } B
$$

Where $A$ and $B$ are the Linguistic values that can be defined by fuzzy set, the If - part of the part of " $x$ is $A$ " is called the antecedent part and the thenpart of the part of " $y$ is $B$ " is called the Consequent or Conclusion part. The antecedent of a fuzzy if-then rule can have multiple parts, which the following rules shows the multiple antecedent rules:

\section{if $e$ is $N B$ and $\dot{e}$ is $M L$ then $T$ is $L L$}

Where $e$ is error, $\dot{e}$ is change of error, $N B$ is Negative Big, $M L$ is Medium Left, $T$ is torque and $L L$ is Large Left. If - then rules have three parts, namely, fuzzify inputs, apply fuzzy operator and apply implication method which in fuzzify inputs the fuzzy statements in the antecedent replaced by the degree of membership, apply fuzzy operator used when the antecedent has multiple parts and replaced by single number between 0 to 1 , this part is a degree of support for the fuzzy rule, and apply implication method used in consequent of fuzzy rule to replaced by the degree of membership. The fuzzy inference engine offers a mechanism for transferring the rule base in fuzzy set which it is divided into two most important methods, namely, Mamdani method and Sugeno method. Mamdani method is one of the common fuzzy inference systems and he designed one of the first fuzzy controllers to control of system engine. Mamdani's fuzzy inference system is divided into four major steps: fuzzification, rule evaluation, aggregation of the rule outputs and defuzzification. Michio Sugeno uses a singleton as a membership function of the rule consequent part. The following definition shows the Mamdani and Sugeno fuzzy rule base

$$
\begin{array}{r}
\text { Mamdani } F . R^{1}: \text { if } \quad x \text { is } A \text { and } \\
y \text { is } B \text { then } z \text { is } C \\
\text { Sugeno } F . R^{1}: \text { if } x \text { is } A \text { and } \\
y \text { is } B \text { then } \quad f(x, y) \text { is } C
\end{array}
$$

When $x$ and $y$ have crisp values fuzzification calculates the membership degrees for antecedent part. Rule evaluation focuses on fuzzy operation $(A N D / O R)$ in the antecedent of the fuzzy rules. The aggregation is used to calculate the output fuzzy set and several methodologies can be used in fuzzy logic controller aggregation, namely, Max-Min aggregation, Sum-Min aggregation, Max-bounded product, Max-drastic product,
Max-bounded sum, Max-algebraic sum and Min-max. Two most common methods that used in fuzzy logic controllers are Max-min aggregation and Sum-min aggregation. Max-min aggregation defined as below.

$$
\begin{aligned}
& \mu_{U}\left(x_{k}, y_{k}, U\right)=\mu_{\cup_{i=1}^{r} F R^{i}}\left(x_{k}, y_{k}, U\right) \\
& =\max \left\{\min _{i=1}^{r}\left[\mu_{R p q}\left(x_{k}, y_{k}\right), \mu_{p_{m}}(U)\right]\right\}
\end{aligned}
$$

The Sum-min aggregation defined as below

$$
\begin{aligned}
& \mu_{U}\left(x_{k}, y_{k}, U\right)=\mu_{\cup_{i=1}^{r} F R^{i}}\left(x_{k}, y_{k}, U\right) \\
& =\sum \min _{i=1}^{r}\left[\mu_{R p q}\left(x_{k}, y_{k}\right), \mu_{p_{m}}(U)\right]
\end{aligned}
$$

Where $r$ is the number of fuzzy rules activated by $x_{k}$ and $y_{k}$ and also $\mu_{\cup_{i=1}^{r} F R^{i}}\left(x_{k}, y_{k}, U\right)$ is a fuzzy interpretation of $i-t h$ rule. Defuzzification is the last step in the fuzzy inference system which it is used to transform fuzzy set to crisp set. Consequently defuzzification's input is the aggregate output and the defuzzification's output is a crisp number. Centre of gravity method $(C O G)$ and Centre of area method $(C O A)$ are two most common defuzzification methods, which COG method used the following equation to calculate the defuzzification

$$
\operatorname{COG}\left(x_{k}, y_{k}\right)=\frac{\sum_{i} U_{i} \sum_{j=1}^{r} \cdot \mu_{u}\left(x_{k}, y_{k}, U_{i}\right)}{\sum_{i} \sum_{j=1}^{r} \cdot \mu_{u}\left(x_{k}, y_{k}, U_{i}\right)}
$$

and $C O A$ method used the following equation to calculate the defuzzification.

$$
\operatorname{COA}\left(x_{k}, y_{k}\right)=\frac{\sum_{i} U_{i} \cdot \mu_{u}\left(x_{k}, y_{k}, U_{i}\right)}{\sum_{i} \mu_{U} \cdot\left(x_{k}, y_{k}, U_{i}\right)}
$$

Where $\operatorname{COG}\left(x_{k}, y_{k}\right)$ and $\operatorname{COA}\left(x_{k}, y_{k}\right)$ illustrates the crisp value of defuzzification output, $U_{i} \in U$ is discrete element of an output of the fuzzy set, $\mu_{U} \cdot\left(x_{k}, y_{k}, U_{i}\right)$ is the fuzzy set membership function, and $r$ is the number of fuzzy rules.

Based on foundation of fuzzy logic methodology; fuzzy logic controller has played important rule to design nonlinear controller for nonlinear and uncertain systems [20-32]. However the application area for fuzzy control is really wide, the basic form for all command types of controllers consists of:

Input fuzzification (binary-to-fuzzy $[\mathrm{B} / \mathrm{F}]$ conversion)

- Fuzzy rule base (knowledge base)

- Inference engine

- Output defuzzification (fuzzy-to-binary conversion).

Fuzzy inference engine shows in figure 2. 


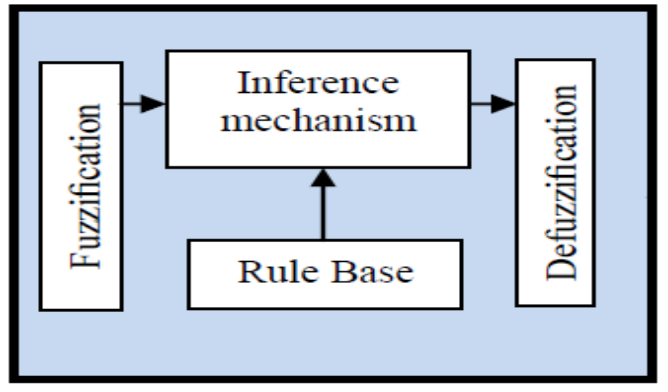

Figure 2. Fuzzy Inference System

\section{Methodology}

This step is focused on the design minimum rule base Mamdani's back stepping fuzzy controller with application to continuum robot manipulator. As mentioned above pure back stepping controller has nonlinear dynamic parameters limitation in presence of uncertainty and external disturbances. In order to solve this challenge fuzzy inference system is serially applied to back stepping controller. The back stepping method is based on mathematical formulation which this method is introduced new variables into it in form depending on the dynamic equation of continuum robot arm. This method is used as feedback linearization in order to solve nonlinearities in the system. Back stepping controller is divided into two main parts; linear part and nonlinear dynamic formulation.. The back stepping controller for continuum robot is calculated by;

$$
U_{B . S}=U_{e q_{B . S}}+D . I
$$

Where $U_{B . S}$ is back stepping output function, $U_{e q_{B . S}}$ is back stepping nonlinear equivalent function which can be written as (32) and $\boldsymbol{I}$ is backstepping control law which calculated by (1)

$$
U_{e q_{B . S}}=[f+C+G]
$$

We have

$$
I=\left[\ddot{e}+K_{1}\left(K_{1}-1\right) \cdot e+\left(K_{1}+K_{2}\right) \cdot \dot{e}\right]
$$

Based on above formulation, FIS in this research has an input $\left(\boldsymbol{N}(\boldsymbol{q}, \dot{\boldsymbol{q}})\right.$ and an output $\left(\boldsymbol{U}_{\text {fuzzy }}\right)$, Figure 3 shows fuzzy inference system.

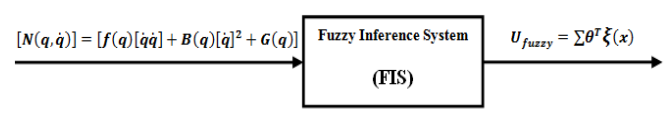

Figure 3. Fuzzy Inference System's input and output

$$
U_{f u z z y}=\sum_{l=1}^{M} \theta^{T} \zeta(x)
$$

To estimate the nonlinear term of back stepping controller fuzzy inference system is used in serial with nonlinear dynamic part.

$$
U_{e q B . S_{f u z z y}}=[(f+C+G)] \times \sum_{l=1}^{M} \theta^{T} \zeta(x)
$$

Based on above formulation the formulation of back stepping fuzzy control is;

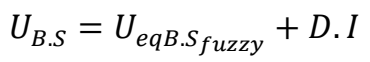

Most robust control designs are based on the assumption that even though the uncertainty vector $\eta$ is unknown, some information is available on its bound.

In designing the robust back stepping controller, a robust term that compensates for the uncertainty in the system dynamics is added to the control law in Equations (13) and (14). The robust control law, therefore, has the following form:

$$
\begin{aligned}
& T_{d}=[\widehat{H}]+\hat{C} \\
& y=\ddot{\tilde{x}}_{1}+\left(\left[K_{p}\right]+\left[K_{d}\right]\right) \dot{\tilde{x}}_{1}+\left[K_{p}\right]\left[K_{d}\right] \tilde{x}_{1}+w
\end{aligned}
$$

The first three terms in Equation (38) ensures the stabilization of the error dynamics in the absence of system uncertainties. The proper choice of $\boldsymbol{w}$ ensures the stability of the system even in the presence of uncertainties. Figure 4 shows a block diagram detailing the steps in the robust back stepping fuzzy control of continuum robot.

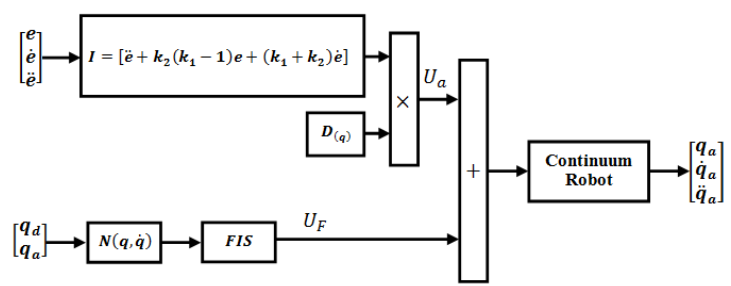

Figure 4. Block diagram of back stepping fuzzy controller for continuum robot

Using the control law in Equation (37) and Equation (38), the system error dynamics in Equation (35) can be rewritten in the following form:

$$
\dot{\xi}=[\tilde{F}] \xi+[D](\pi-\mathrm{w})
$$

where

$$
\begin{aligned}
& {[\tilde{F}]=([F]-[D][K])=} \\
& {\left[\begin{array}{cc}
{[0]} & {[I]} \\
-\left[K_{p}\right]\left[K_{d}\right] & -\left[K_{p}\right]-\left[K_{d}\right]
\end{array}\right]} \\
& K=\left[\left[K_{p}\right]\left[K_{d}\right] \quad\left[K_{p}\right]+\left[K_{d}\right]\right]^{T}
\end{aligned}
$$


When there are no uncertainties in the system dynamics, the robust term in the applied controller return is identically zero and the control law returns to the back stepping control developed in the previous section. Figure 2 shows a block diagram of the robust back stepping controller.

The stability considerations and the design for the robust controller are determined using Lyapunov methods. The following positive definite quadratic function is selected as a Lyapunov function:

$$
V_{1}=\xi^{T}[Q] \xi>0 \quad \forall \xi \neq 0
$$

Where [Q] $\in \mathrm{R}^{6 \times 6}$ is a positive definite matrix. The time derivative of the Lyapunov function along the trajectories of the error dynamics results in the following equation:

$$
\begin{aligned}
& \dot{V}_{1}= \\
& \xi^{T}\left([\tilde{F}]^{T}[Q]+[Q][\tilde{F}]\right) \xi+2 \xi^{T}[Q][D](\eta-w)
\end{aligned}
$$

Since, for a negative definite matrix $[\widetilde{\boldsymbol{F}}]$; a positive definite matrix $[\boldsymbol{Q}]$; and a symmetric positive definite matrix $[\boldsymbol{P}]$, the following identity holds;

$$
[\widetilde{F}]^{T}[Q]+[Q][\tilde{F}]=-[P]
$$

the time derivative of the Lyapunov function in Equation (44) can therefore be rewritten as

$$
\dot{V}_{1}=-\xi^{T}[P] \xi+2 \xi^{T}[Q][D](\eta-w)
$$

The time derivative of the Lyapunov function is strictly negative definite if the second term in the above equation is either negative or zero. The error dynamics converge to zero when the time derivative of the Lyapunov function in Equation (45) is negative definite. Selecting the robust control term $\mathrm{w}$ as

$$
w=\frac{\rho}{\|z\|} z \quad \rho>0
$$

Where $\mathrm{z}=[\mathrm{D}]^{\mathrm{T}}[\mathrm{Q}] \xi$ substituting it into Equation (46) results in the following expression for the time derivative of the Lyapunov function.

$$
\dot{V}_{1}=-\xi^{T}[P] \xi+2 z^{T}\left(\eta-\frac{\rho}{\|z\|} z\right)
$$

According to the following inequality,

$$
z^{T}(\eta-w) \leq\|z\|\|\eta\|-\rho\|z\|
$$

$z^{T}\left(\eta-\frac{\rho}{\|z\|} z\right)$ is always bounded from above by $\|z\|(\|\eta\|-\rho)$. Therefore, selecting p such that

$$
\rho \geq\|\eta\| \quad \forall x_{1} \dot{x}_{1} \ddot{x}_{1 d}
$$

results in the negative definiteness of the time derivative of the Lyapunov function along the dynamics of $\xi$.

With the definition of $\eta$ given in Equation (49), the following bound can be put on the uncertainty term $\eta$.

$$
\begin{aligned}
& \|\eta\|=\left\|I-[H]^{-1}[\widehat{H}]\right\|\left(\left\|\ddot{x}_{1 d}\right\|+\|[K]\|\|\xi\|+\right. \\
& \|[w]\|)+\left\|[H]^{-1}\right\|\|\tilde{\eta}\| \leq \kappa Q_{M}+ \\
& \kappa\|[K]\|\|\xi\|+\kappa \rho+\left[H_{M}\right] \theta
\end{aligned}
$$

Using the inequalities in Equations (49) and (50), $\rho$ is solved to give the following relationship

$$
\rho \geq \frac{1}{1-\kappa}\left(\kappa Q_{M}+\kappa\|[K]\|\|\xi\|+\left[H_{M}\right] \theta\right)
$$

The choice of $\rho$ from Equation (51) ensures that the time derivative of the Lyapunov function is negative definite. This results in the stability of the error dynamics.

$$
\begin{gathered}
\dot{V}_{1}=-\xi^{T}[P] \xi+2 z^{T}\left(\eta-\frac{\rho}{\|z\|} z\right)<0 \\
\forall \xi \neq 0
\end{gathered}
$$

\section{Result and Discussion}

Robust back stepping fuzzy controller (FBSC) was tested to Step response trajectory. In this simulation, to control position of continuum robot is moved from home to final position without and with external disturbance. The simulation was implemented in MATLAB/SIMULINK environment. These systems are tested by band limited white noise with a predefined $40 \%$ of relative to the input signal amplitude. This type of noise is used to external disturbance in continuous and hybrid systems and applied to nonlinear dynamic of these controllers.

Tracking performances: Figure 5 shows tracking performance for FBSC and BSC without disturbance.

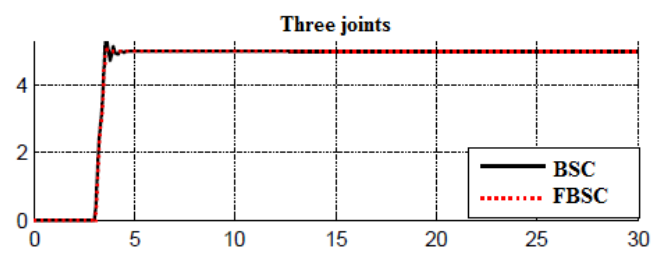

Figure 5. FBSC and BSC for first, second and third joint trajectory

By comparing step response trajectory without disturbance in BSC and FBSC, it is found that the FBSC's overshoot (1.4\%) is lower than BSC's (1.6\%).

Disturbance rejection: Figure 6 has shown the power disturbance elimination in BSC and FBSC. The main target in this controller is disturbance rejection as well as the other responses. A band limited white noise with predefined of $40 \%$ the power of input signal is applied to BSC and FBSC. It found fairly fluctuations in trajectory responses. As mentioned earlier, BSC works very well 
when all parameters are known, or we have a limitation uncertainty in parameters.

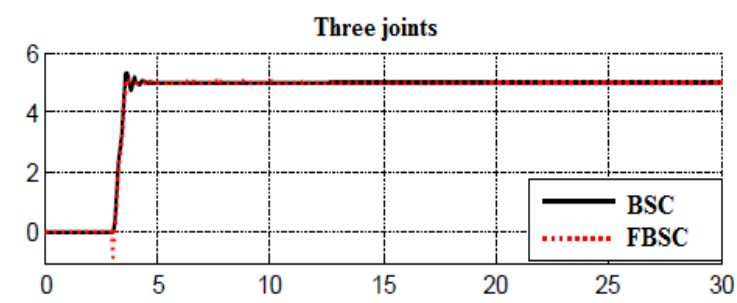

Figure 6. FBSC and BSC for first, second and third joint trajectory with disturbance.

Among above graph (6) relating to step trajectory following with external disturbance, BSC and FBSC have fairly fluctuations. By comparing some control parameters such as overshoot, rise time, steady state and RMS error it is computed that the FBSC's overshoot $\mathbf{( 1 . 6 \% )}$ is lower than BSC's (3\%). Both of them have about the same rise time; FBSC (0.5 sec) and BSC (0.49 sec).

\section{Conclusion}

Continuum robot is a nonlinear high degree serial robot. The dynamic parameters of this system are highly nonlinear. To control of this system robust back stepping methodology is introduced. Back stepping controller (BSC) is an influential robust nonlinear controller to certain and partly uncertain systems. When all dynamic and physical parameters are known BSC works superbly; practically a large amount of systems have uncertainties and fuzzy model base BSC is used. Robust back stepping fuzzy controller (FBSC) is a mathematical model base method to off-line control of highly nonlinear systems such as continuum robot. Based on this research FBSC is more robust in presence of uncertainties and external disturbance however it is off-line tuning methodology.

\section{Acknowledgment}

The authors would like to thank the anonymous reviewers for their careful reading of this paper and for their helpful comments. This work was supported by the Institute of Advanced Science and Technology (IRANSSP) Research and Development Corporation Program of Iran under grant no. 2012-Persian Gulf-4B.

\section{References:}

[1] T. R. Kurfess, Robotics and automation handbook: CRC, 2005.

[2] J. J. E. Slotine and W. Li, Applied nonlinear control vol. 461: Prentice hall Englewood Cliffs, NJ, 1991.

[3] L. Cheng, et al., "Multi-agent based adaptive consensus control for multiple manipulators with kinematic uncertainties," 2008, pp. 189-194.
[4] J. J. D'Azzo, et al., Linear control system analysis and design with MATLAB: CRC, 2003.

[5] B. Siciliano and O. Khatib, Springer handbook of robotics: Springer-Verlag New York Inc, 2008.

[6] I. Boiko, et al., "Analysis of chattering in systems with second-order sliding modes," IEEE Transactions on Automatic Control, vol. 52, pp. 2085-2102, 2007.

[7] J. Wang, et al., "Indirect adaptive fuzzy sliding mode control: Part I: fuzzy switching," Fuzzy Sets and Systems, vol. 122, pp. 21-30, 2001.

[8] F. Piltan, et al., "Artificial Control of Nonlinear Second Order Systems Based on AFGSMC," Australian Journal of Basic and Applied Sciences, 5(6), pp. 509-522, 2011.

[9] V. Utkin, "Variable structure systems with sliding modes," Automatic Control, IEEE Transactions on, vol. 22, pp. 212-222, 2002.

[10] R. A. DeCarlo, et al., "Variable structure control of nonlinear multivariable systems: a tutorial," Proceedings of the IEEE, vol. 76, pp. 212-232, 2002.

[11] K. D. Young, et al., "A control engineer's guide to sliding mode control," 2002, pp. 1-14.

[12] Samira Soltani \& Farzin Piltan, "Design Artificial Nonlinear Controller Based on Computed Torque like Controller with Tunable Gain”, World Applied Science Journal (WASJ), 14 (9): 1306-1312, 2011.

[13] Farzin Piltan, Mohammadali Dialame, Abbas Zare \& Ali Badri,"Design Novel Lookup Table Changed Auto Tuning FSMC:Applied to Robot Manipulator", International Journal of Engineering, 6 (1):25-41, 2012.

[14] Farzin Piltan, Mohammad Keshavarz, Ali Badri \& Arash Zargari,“Design Novel Nonlinear Controller Applied to RobotManipulator: Design New Feedback Linearization Fuzzy Controller with Minimum Rule Base Tuning Method", International Journal of Robotics and Automation,3 (1):1-12, 2012.

[15] Farzin Piltan, Iman Nazari, Sobhan Siamak, Payman Ferdosali,"Methodology of FPGA-Based Mathematical error-Based Tuning Sliding Mode Controller", International Journal of Control and Automation, 5(1), 89-118, 2012.

[16] Farzin Piltan, Bamdad Boroomand, Arman Jahed \& Hossein Rezaie, "Methodology of Mathematical Error-Based Tuning Sliding Mode Controller", International Journal of Engineering, 6 (2):96-117, 2012.

[17] Farzin Piltan, Sara Emamzadeh, Zahra Hivand, Fatemeh Shahriyari \& Mina Mirazaei, "PUMA-560 Robot Manipulator Position Sliding Mode Control Methods Using MATLAB/SIMULINK and Their Integration into Graduate/Undergraduate Nonlinear Control, Robotics and MATLAB Courses", International Journal of Robotics and Automation, 3(3):106-150, 2012.

[18] Farzin Piltan, Ali Hosainpour, Ebrahim Mazlomian, Mohammad Shamsodini, Mohammad H. Yarmahmoudi, "Online Tuning Chattering Free 
Sliding Mode Fuzzy Control Design: Lyapunov Approach", International Journal of Robotics and Automation, 3(3):77-105, 2012.

[19] Farzin Piltan, Mina Mirzaei, Forouzan Shahriari, Iman Nazari, Sara Emamzadeh, "Design Baseline Computed Torque Controller", International Journal of Engineering, 6(3): 129-141, 2012.

[20] Farzin Piltan, Mohammad H. Yarmahmoudi, Mohammad Shamsodini, Ebrahim Mazlomian, Ali Hosainpour, "PUMA-560 Robot Manipulator Position Computed Torque Control Methods Using MATLAB/SIMULINK and Their Integration into Graduate Nonlinear Control and MATLAB Courses", International Journal of Robotics and Automation, 3(3): 167-191, 2012.

[21] Farzin Piltan, Hossein Rezaie, Bamdad Boroomand, Arman Jahed, "Design Robust Backstepping on-line Tuning Feedback Linearization Control Applied to IC Engine", International Journal of Advance Science and Technology, 11:40-22, 2012.

[22] Farzin Piltan, Mohammad R. Rashidian, Mohammad Shamsodini and Sadeq Allahdadi, Effect of Rule Base on the Fuzzy-Based Tuning Fuzzy Sliding Mode Controller: Applied to 2nd Order Nonlinear System", International Journal of Advanced Science and Technology, 46:39-70, 2012.

[23] Farzin Piltan, Arman Jahed, Hossein Rezaie and Bamdad Boroomand, "Methodology of Robust Linear On-line High Speed Tuning for Stable Sliding Mode Controller: Applied to Nonlinear System", International Journal of Control and Automation, 5(3): 217-236, 2012.

[24] Farzin Piltan, Bamdad Boroomand, Arman Jahed and Hossein Rezaie, "Performance-Based Adaptive Gradient Descent Optimal Coefficient Fuzzy Sliding Mode Methodology", International Journal of Intelligent Systems and Applications, , vol.4, no.11, pp.40-52, 2012.

[25] Farzin Piltan, Mehdi Akbari, Mojdeh Piran , Mansour Bazregar, 'Design Model Free Switching Gain Scheduling Baseline Controller with Application to Automotive Engine", International Journal of Information Technology and Computer Science, vol.5, no.1, pp.65-73, 2013.DOI: 10.5815/ijitcs.2013.01.07.

[26] Farzin Piltan, Mojdeh Piran , Mansour Bazregar, Mehdi Akbari, "Design High Impact Fuzzy Baseline Variable Structure Methodology to Artificial Adjust Fuel Ratio", International Journal of Intelligent Systems and Applications, vol.5, no.2, pp.59-70, 2013.DOI: 10.5815/ijisa.2013.02.0.

[27] Farzin Piltan, M. Bazregar, M. kamgari, M. Akbari and M. Piran, "Adjust the Fuel Ratio by High Impact Chattering Free Sliding Methodology with Application to Automotive Engine", International Journal of Hybrid Information Technology, 6(1), 2013.

[28] Farzin Piltan, S. Zare, F. ShahryarZadeh, M. Mansoorzadeh, M. kamgari, "Supervised Optimization of Fuel Ratio in IC Engine Based on
Design Baseline Computed Fuel Methodology", International Journal of Information Technology and Computer Science, vol.5, no.4, pp.76-84, 2013.DOI: 10.5815/ijitcs.2013.04.09.

[29] Farzin Piltan, M. Mansoorzadeh, S. Zare, F.Shahryarzadeh, M. Akbari, "Artificial Tune of Fuel Ratio: Design a Novel SISO Fuzzy Backstepping Adaptive Variable Structure Control”, International Journal of Electrical and Computer Engineering, 3(2), 2013.

[30] M. Bazregar, Farzin Piltan, A. Nabaee and M.M. Ebrahimi, "Parallel Soft Computing Control Optimization Algorithm for Uncertainty Dynamic Systems", International Journal of Advanced Science and Technology, 51, 2013.

[31] Farzin Piltan, M.H. Yarmahmoudi, M. Mirzaei, S. Emamzadeh, Z. Hivand, "Design Novel Fuzzy Robust Feedback Linearization Control with Application to Robot Manipulator", International Journal of Intelligent Systems and Applications , vol.5, no.5, pp.1-10, 2013.DOI: 10.5815/ijisa.2013.05.01.

[32] Sh. Tayebi Haghighi, S. Soltani, Farzin Piltan, M. kamgari, S. Zare, "Evaluation Performance of IC Engine: Linear Tunable Gain Computed Torque Controller Vs. Sliding Mode Controller", International Journal of Intelligent Systems and Applications, vol.5, no.6, pp.78-88, 2013.DOI: 10.5815/ijisa.2013.06.10.

[33] Amin Jalali, Farzin Piltan, M. Keshtgar, M. Jalali, "Colonial Competitive Optimization Sliding Mode Controller with Application to Robot Manipulator", International Journal of Intelligent Systems and Applications, vol.5, no.7, pp.50-56, 2013. DOI: 10.5815/ijisa.2013.07.07.

[34] Salehi, Farzin Piltan, M. Mousavi, A. Khajeh, M. R. Rashidian, "Intelligent Robust Feed-forward Fuzzy Feedback Linearization Estimation of PID Control with Application to Continuum Robot", International Journal of Information Engineering and Electronic Business, vol.5, no.1, pp.1-16, 2013. DOI: 10.5815/ijieeb.2013.01.01.

[35] Farzin Piltan, M.J. Rafaati, F. Khazaeni, A. Hosainpour, S. Soltani, "A Design High Impact Lyapunov Fuzzy PD-Plus-Gravity Controller with Application to Rigid Manipulator", International Journal of Information Engineering and Electronic Business, vol.5, no.1, pp.17-25, 2013. DOI: 10.5815/ijieeb.2013.01.02.

[36] Amin Jalali, Farzin Piltan, A. Gavahian, M. Jalali, M. Adibi, "Model-Free Adaptive Fuzzy Sliding Mode Controller Optimized by Particle Swarm for Robot manipulator", International Journal of Information Engineering and Electronic Business, vol.5, no.1, pp.68-78, 2013. DOI: 10.5815/ijieeb.2013.01.08.

[37] Farzin Piltan, F. ShahryarZadeh ,M. Mansoorzadeh , M. kamgari, S. Zare, "Robust Fuzzy PD Method with Parallel Computed Fuel Ratio Estimation Applied to Automotive Engine“, International 
Journal of Intelligent Systems and Applications, vol.5, no.8, pp.83-92, 2013. DOI: 10.5815/ijisa.2013.08.10.

[38] Farzin Piltan, A. Nabaee, M.M. Ebrahimi, M. Bazregar, "Design Robust Fuzzy Sliding Mode Control Technique for Robot Manipulator Systems with Modeling Uncertainties", International Journal of Information Technology and Computer Science, vol.5, no.8, pp.123-135, 2013. DOI: 10.5815/ijitcs.2013.08.12.

[39] Farzin Piltan, M. Mansoorzadeh, M. Akbari, S. Zare, F. ShahryarZadeh "Management of Environmental Pollution by Intelligent Control of Fuel in an Internal Combustion Engine" Global Journal of Biodiversity Science And Management, 3(1), 2013.

[40] M. M. Ebrahimit Farzin Piltan, M. Bazregar and A.R. Nabaee, "Intelligent Robust Fuzzy-Parallel Optimization Control of a Continuum Robot Manipulator", International Journal of Control and Automation, 6(3), 2013.

[41] O.R. Sadrnia, Farzin Piltan, M. Jafari, M. Eram and M. Shamsodini, "Design PID Estimator Fuzzy plus Backstepping to Control of Uncertain Continuum Robot", International Journal of Hybrid Information Technology, 6(4), 2013.

[42] AminJalali, Farzin Piltan, H. Hashemzadeh, A. Hasiri, M.R Hashemzadeh, "Design Novel Soft Computing Backstepping Controller with Application to Nonlinear Dynamic Uncertain System", International Journal of Intelligent Systems and Applications, vol.5, no.10, pp.93-105, 2013. DOI: 10.5815/ijisa.2013.10.12.

[43] M. Moosavi, M. Eram, A. Khajeh, O. Mahmoudi and Farzin Piltan, "Design New Artificial Intelligence Base Modified PID Hybrid Controller for Highly Nonlinear System", International Journal of Advanced Science and Technology, 57, 2013.

[44] S. Zahmatkesh, Farzin Piltan, K. Heidari, M. Shamsodini, S. Heidari, "Artificial Error Tuning Based on Design a Novel SISO Fuzzy Backstepping Adaptive Variable Structure Control" International Journal of Intelligent Systems and Applications, vol.5, no.11, pp.34-46, 2013.DOI: 10.5815/ijisa.2013.11.04.

[45] S. Heidari, Farzin Piltan, M. Shamsodini, K. Heidari and S. Zahmatkesh, "Design New Nonlinear Controller with Parallel Fuzzy Inference System Compensator to Control of Continuum Robot Manipulator",International Journal of Control and Automation, 6(4), 2013.

[46] FarzinPiltan, M. Kamgari, S. Zare, F. ShahryarZadeh, M. Mansoorzadeh, "Design Novel Model Reference Artificial Intelligence Based Methodology to Optimized Fuel Ratio in IC Engine", International Journal of Information Engineering and Electronic Business, vol.5, no.2, pp.44-51, 2013. DOI: 10.5815/ijieeb.2013.02.07.

[47] Farzin Piltan, Mehdi Eram, Mohammad Taghavi, Omid Reza Sadrnia, Mahdi Jafari,"Nonlinear Fuzzy Model-base Technique to Compensate Highly
Nonlinear Continuum Robot Manipulator", IJISA, vol.5, no.12, pp.135-148, 2013. DOI: 10.5815/ijisa.2013.12.12.

[48] Amin Jalali, Farzin Piltan, Mohammadreza Hashemzadeh, Fatemeh BibakVaravi, Hossein Hashemzadeh,"Design Parallel Linear PD Compensation by Fuzzy Sliding Compensator for Continuum Robot", IJITCS, vol.5, no.12, pp.97-112, 2013. DOI: 10.5815/ijitcs.2013.12.12.

[49] Farzin Piltan, A. Hosainpour, S. Emamzadeh, I. Nazari, M. Mirzaie, "Design Sliding Mode Controller of with Parallel Fuzzy Inference System Compensator to Control of Robot Manipulator", International Journal of Robotics and Automation, Vol. 2, No. 4, December 2013, pp. 149 162.

[50] Farzin Piltan, Mahdi Jafari, Mehdi Eram, Omid Mahmoudi, Omid Reza Sadrnia, "Design Artificial Intelligence-Based Switching PD plus Gravity for Highly Nonlinear Second Order System", International Journal of Engineering and Manufacturing, vol.3, no.1, pp.38-57, 2013.DOI: 10.5815/ijem.2013.01.04.

[51] Farzin Piltan, Sara Emamzadeh, Sara Heidari, Samaneh Zahmatkesh, Kamran Heidari, "Design Artificial Intelligent Parallel Feedback Linearization of PID Control with Application to Continuum Robot", International Journal of Engineering and Manufacturing, vol.3, no.2, pp.51-72, 2013.DOI: 10.5815/ijem.2013.02.04.

[52] Mohammad Mahdi Ebrahimi, Farzin Piltan, Mansour Bazregar, AliReza Nabaee,"Artificial Chattering Free on-line Modified Sliding Mode Algorithm: Applied in Continuum Robot Manipulator", International Journal of Information Engineering and Electronic Business, vol.5, no.5, pp.57-69, 2013. DOI: 10.5815/ijieeb.2013.05.08.

[53] Arman Jahed, Farzin Piltan, Hossein Rezaie, Bamdad Boroomand, "Design Computed Torque Controller with Parallel Fuzzy Inference System Compensator to Control of Robot Manipulator", International Journal of Information Engineering and Electronic Business, vol.5, no.3, pp.66-77, 2013 DOI: 10.5815/ijieeb.2013.03.08.

[54] Mohammad Shamsodini, Farzin Piltan, Mahdi Jafari, Omid reza Sadrnia, Omid Mahmoudi,"Design Modified Fuzzy Hybrid Technique: Tuning By GDO", IJMECS, vol.5, no.8, pp.58-72, 2013.DOI: 10.5815/ijmecs.2013.08.07.

[55] Mahdi Mirshekaran, Farzin Piltan, Zahra Esmaeili, Tannaz Khajeaian,Meysam Kazeminasab,"Design Sliding Mode Modified Fuzzy Linear Controller with Application to Flexible Robot Manipulator", IJMECS, vol.5, no.10, pp.53-63, 2013.DOI: 10.5815/ijmecs.2013.10.07.

[56] Meysam Kazeminasab, Farzin Piltan, Zahra Esmaeili, Mahdi Mirshekaran, Alireza Salehi ,"Design Parallel Fuzzy Partly Inverse Dynamic Method plus Gravity Control for Highly Nonlinear Continuum Robot", IJISA, vol.6, no.1, pp.112-123, 2014. DOI: 10.5815/ijisa.2014.01.12. 
[57] Mansour Bazregar, Farzin Piltan, Mehdi Akbari, Mojdeh Piran,"Management of Automotive Engine Based on Stable Fuzzy Technique with Parallel Sliding Mode Optimization", IJITCS, vol.6, no.1, pp.101-107, 2014. DOI: 10.5815/ijitcs.2014.01.12.

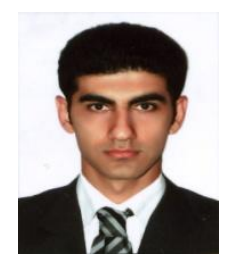

Kamran Heidari is currently working as a co researcher in Control and Robotic Lab at the institute of advance science and technology, SSP research and development institute. His current research interests are in the area of nonlinear control, artificial control system and robotics.

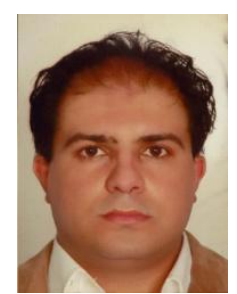

Farzin Piltan was born on 1975, Shiraz, Iran. In 2004 he is jointed the research and development company, SSP Co, Shiraz, Iran. In addition to 7 textbooks, Farzin Piltan is the main author of more than 95 scientific papers in refereed journals. He is supervised and managed nonlinear control and artificial intelligent Lab, Institute of Advance Science and Technology for over 3 years. He also has highly skilled in embeded system controller and device programming including FPGA and CPLD. He is editorial review board member for 'international journal of control and automation (IJCA), Australia, ISSN: 2005-4297; 'International Journal of Intelligent System and Applications (IJISA)', Hong Kong, ISSN:2074-9058; 'IAES international journal of robotics and automation, Malaysia, ISSN:2089-4856; 'International Journal of Reconfigurable and Embedded Systems', Malaysia, ISSN:2089-4864. His current research interests are nonlinear control, artificial control system and applied to FPGA, robotics and artificial nonlinear control and IC engine modeling and control.

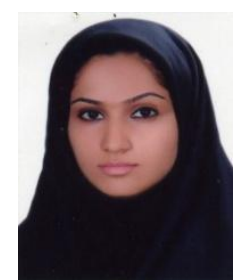

Samaneh Zahmatkesh is currently working as a co researcher in Control and Robotic Lab at the inistitute of advance science and technology, SSP research and development institute. Her current research interests are in the area of nonlinear control, artificial control system and robotics.

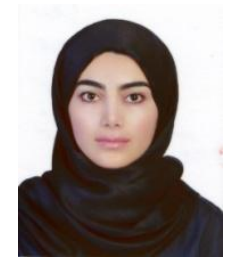

Sara Heidari is currently working as a co researcher in Control and Robotic Lab at the inistitute of advance science and technology, SSP research and development institute. Her current research interests are in the area of nonlinear control, artificial control system and robotics.

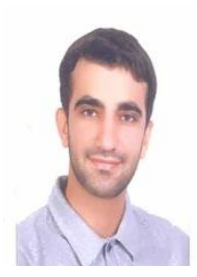

Mahdi Jafari is currently working as a co researcher in Control and Robotic Lab at the institute of advance science and technology, SSP research and development institute. He is a Master in field of Electrical Communication Enginnring at Shiraz University. His current research interests are in the area of nonlinear control, artificial control system, and robotics. 